IZA DP No. 1748

Using Efficiency Analysis to Measure Individual Well-Being with an Illustration for Catalonia

Xavi Ramos

September 2005 


\title{
Using Efficiency Analysis to Measure Individual Well-Being with an Illustration for Catalonia
}

\author{
Xavi Ramos \\ Universitat Autònoma de Barcelona \\ and IZA Bonn
}

Discussion Paper No. 1748

September 2005

\author{
IZA \\ P.O. Box 7240 \\ 53072 Bonn \\ Germany \\ Phone: +49-228-3894-0 \\ Fax: +49-228-3894-180 \\ Email: iza@iza.org
}

Any opinions expressed here are those of the author(s) and not those of the institute. Research disseminated by IZA may include views on policy, but the institute itself takes no institutional policy positions.

The Institute for the Study of Labor (IZA) in Bonn is a local and virtual international research center and a place of communication between science, politics and business. IZA is an independent nonprofit company supported by Deutsche Post World Net. The center is associated with the University of Bonn and offers a stimulating research environment through its research networks, research support, and visitors and doctoral programs. IZA engages in (i) original and internationally competitive research in all fields of labor economics, (ii) development of policy concepts, and (iii) dissemination of research results and concepts to the interested public.

IZA Discussion Papers often represent preliminary work and are circulated to encourage discussion. Citation of such a paper should account for its provisional character. A revised version may be available directly from the author. 
IZA Discussion Paper No. 1748

September 2005

\section{ABSTRACT}

\section{Using Efficiency Analysis to Measure Individual Well-Being with an Illustration for Catalonia*}

This paper shows how distance functions, a tool typically employed in production economics to measure the distance between a set of inputs and a set of outputs, can be employed to approximate a composite measure encompassing the many dimensions of well-being. It also illustrates how to implement the methodology originally put forth by Lovell et al. (1994), using new data for Catalonia. We draw policy implications and critically appraise the discussed methodology suggesting avenues for further research.

JEL Classification: $\quad$ D31, D63, I31, I32

Keywords: $\quad$ well-being, multidimensional poverty, distance function, Catalonia

Corresponding author:

Xavi Ramos

Departament d'Economia Aplicada

Universitat Autònoma de Barcelona

Edifici B

08193 Bellaterra

Spain

Email:xavi.ramos@uab.es

* This paper was prepared for the UNDP-IPC Conference on The Many Dimensions of Poverty, Brasilia, 29-31 August 2005. I would like to thank the participants of the conference and Ada Ferrer-iCarbonell for their comments. The usual disclaimer applies. 
One could be well-off, without being well (due to health problems). One could be well, without being able to lead the life he or she wanted (due to cultural restrictions and bounds). One could have got the life he or she wanted, without being happy (due to psychological problems). One could be happy, without having much freedom (due to society's norms). One could have a good deal of freedom, without achieving much (due to lack of self-confidence or self-esteem). We can go on. [Sen, 1999:3; parentheses are ours]

\section{I NTRODUCTI ON}

Nowadays very few people would question the multidimensional nature of well-being, and if you are not entirely convinced, the opening quote by Amartya Sen will hopefully help. In recent years we have witnessed an increasing interest in the assessment of well-being -or of other

related concepts such as standard of living or quality of life- from a multidimensional perspective. Certainly, some theoretical developments, such as Sen's capability approach, together with the increasing availability of individual information on the many dimensions and facets of the concept of well-being, have contributed to the search for reasonable empirical strategies to the measurement of well-being in a multidimensional fashion. Indeed, the different contributions to the various sessions concerned with the Quantification of Multidimensional Poverty demonstrate the vitality of research in this field. One such approach is the method originally proposed by Lovell et al. (1994), which basically consists in employing distance functions, a tool typically employed in production economics to measure the distance between a set of inputs and a set of outputs, to the measurement of individual-well-being. 
This paper shows in a simple manner how distance functions can be used to measure well-being, and then provides an illustration with Catalan data. Section 2 defines and briefly discusses the main features of distance functions in their original context of production economics, and then proceeds to explaining how to construct scalar measures of individual well-being using distance functions, following Lovell et al. (1994). Section 3 reviews the scarce existing literature which measures well-being and related concepts using distance functions, while Sections 4 and 5 present an illustration for Catalonia and the data used for the analysis. Finally, Sections 6 and 7 conclude with some policy implementation remarks and comments on the suitability of the distance function approach to the assessment of individual wellbeing and multidimensional poverty.

\section{On the Usage of Distance functions to Measure Well-being ${ }^{1}$}

The approach I am using to measure individual well-being builds on the methodological similarities between efficiency analysis and the multidimensional assessment of individual well-being. In both instances the analyst faces the problem of summarizing or collapsing a whole lot of information into only one dimension. When measuring efficiency, for instance, our concern may be on the different amounts of inputs employed by a firm to produce a given set of outputs. Likewise, when considering the measurement of well-being one has to bring all the relevant dimensions into a scalar measure or index, which approximates the level of well-being enjoyed by each individual.

\footnotetext{
${ }^{1}$ This section draws on some of my previous co-authored work on the field, namely Deutsch et al. (2003) and Ramos and Silber (2005). This section, however, wants to be more explicit and intuitive than the discussions found in our previous papers.
} 
Our empirical strategy for the construction of the well-being index requires the estimation of distance functions, which are widely used in production economics to deal with the multi-output nature of production. ${ }^{2}$ A distance function may have either an input orientation or an output orientation. Next, I briefly outline the vary basics of distance functions paying special attention to the intuition rather than to the more formal aspects.

\section{Output Distance Functions}

Intuitively, an output distance function measures the extent to which the output vector may be proportionally expanded or increased with the input vector held fixed. Consider a simple case where two outputs, $\mathrm{y}_{1}$ and $\mathrm{y}_{2}$ are produced using an input vector $\mathbf{x}$. Figure 1 illustrates the concept of an output distance function for a given input vector. Let us first define the output set, $\mathrm{P}(\mathbf{x})$, as the various output combinations $\left(y_{1}, y_{2}\right)$ that could be produced given input vector $\mathbf{x}$. In Figure 1 the output set corresponds to the area bounded by the two axes and the production possibility frontier, $\operatorname{PPF}(\mathbf{x})$, which depicts the maximum amongst these output combinations, or in other words, the maximum amount of one of the outputs, say $y_{1}$, that could be produced for a given amount of the other output, $y_{2}$, and the input vector, $\mathbf{x}$. Clearly, the output vector $A=\left(y_{1 A}, y_{2 A}\right)$, being inside the output set, could be proportionally expanded to point $B=\left(y_{1 B}, y_{2 B}\right)$, which as it lies on the

\footnotetext{
2 Other alternative methods commonly used in the production economics literature try to circumvent the problems that arise due to the many dimensions of the multi-output nature of production by resorting to techniques, which allow them to work with the traditional singleoutput production framework. Such methods include aggregating the multiple outputs into a single output measure or using dual representations of the production technology, such as cost or profit functions. The advantages of distance functions over these methods are that (i) price information, which is often difficult to obtain, is not required, and (ii) that no behavioural assumptions, such as profit maximization, are needed. These two features are also positive features for the measurement of well-being.
} 
production possibility frontier cannot be proportionally expanded any longer without changing input vector $\mathbf{x}$-or the production technology.

The distance function for point $A$ measures the distance (along ray $0 \mathrm{~B}$ ) between this point and the $\operatorname{PPF}(\mathbf{x})$, as the inverse of the factor by which the production of all output quantities could be increased while still remaining within the feasible production possibility set for a given input vector. That is, the distance function of the firm using input vector $\mathbf{x}$ to produce the output levels defined by point $A$ equals the ratio $(\mathrm{OA} / \mathrm{OB})=\theta$, whereas the distance function value of point $\mathrm{B}$ is 1 .

More formally, the output distance function, $\mathrm{D}_{\text {out }}(\mathbf{x}, \mathbf{y})$, is defined as

$$
\mathrm{D}_{\text {out }}(\mathbf{x}, \mathbf{y})=\min \{\theta:(\mathbf{y} / \theta) \in \mathrm{P}(\mathbf{x})\}
$$

where $\theta$ is a scalar, and $\mathbf{y} \in \mathrm{R}_{++}{ }^{\mathrm{M}}$ and $\mathbf{x} \in \mathrm{R}_{++}{ }^{\mathrm{N}}$ are output and input vectors respectively. ${ }^{3}$ Output distance functions have some properties that will show useful when applied to the measurement of well-being. They are nondecreasing, positively linearly homogeneous and concave in $\mathbf{y}$, and decreasing in $\mathbf{x}$. As pointed out before, $D_{\text {out }}(\mathbf{x}, \mathbf{y}) \leq 1$ if $\mathbf{y}$ belongs to $P(\mathbf{x})$, being equal to one if it lies on the $\operatorname{PPF}(\mathbf{x})$.

\section{I nput Distance Functions}

An input distance function is defined in a similar way. However, rather than saying how the output vector may be proportionally expanded given an input vector, it considers by how much the input vector may be proportionally contracted given an output vector.

\footnotetext{
${ }^{3}$ For a more detailed and technical discussion of distance functions and related topics see Coelli et al. (1998). Ramos and Silber (2005), Deutsch et al. (2003) and Lovell et al. (1994) establish the link between distance functions and the analysis of well-being.
} 
Figure 2 illustrates the concept of an input distance function. Now, we should consider input sets and isoquants rather than output sets and production possibility frontiers. An input set, $L(\mathbf{y})$ indicates the set of all input vectors, $\mathbf{x}$, which can produce the output vector $\mathbf{y}$. In Figure 2 , the input set is the area bounded from below by the isoquant, $\mathrm{IQ}(\mathbf{y})$, which depicts the minimum amongst these input combinations, for each proportion of inputs. Now, the input vector $A=\left(x_{1 A}, x_{2 A}\right)$, being inside the input set, could be proportionally contracted to point $B$ $=\left(\mathrm{X}_{1 \mathrm{~B}}, \mathrm{X}_{2 \mathrm{~B}}\right)$, which as it lies on the isoquant cannot be proportionally contracted any longer without changing the output vector $\mathbf{y}$-or the production technology.

The distance function for point $A$ measures the distance (along ray $0 A$ ) between this point and the IQ(y), as the inverse of the factor by which the production of all input quantities could be reduced while still remaining within the feasible isoquant for a given output vector. That is, the distance function of the firm producing output set $\mathbf{y}$ using the input levels defined by point $A$ equals the ratio $(O A / O B)=\rho$, whereas the distance function value of point $B$ is 1 .

More formally, the input distance function, $D_{\text {in }}(\mathbf{x}, \mathbf{y})$, is defined as

$$
\mathrm{D}_{\text {in }}(\mathbf{x}, \mathbf{y})=\max \{\rho:(\mathbf{x} / \rho) \in \mathrm{L}(\mathbf{y})\}
$$

where $\rho$ is the scalar that measures the distance. Input distance functions also have some properties that will show useful when applied to the measurement of well-being. They are nondecreasing, positively linearly homogeneous and concave in $\mathbf{x}$, and decreasing in $\mathbf{y}$. As 
pointed out before, $D_{\text {in }}(\mathbf{x}, \mathbf{y}) \geq 1$ if $\mathbf{x}$ belongs to $L(\mathbf{y})$, being equal to one if it lies on the $\mathrm{IQ}(\mathbf{y})$.

Let us now proceed to see how distance functions can be employed to estimate a measure of well-being that considers several dimensions of an individuals' life. I will assume that individual's well-being stems from the achievement or realisation in different dimensions or facets of life - which could arguably be identified with Sen's functionings. ${ }^{4}$ Then, in line with Dasgupta (1990), I shall use input distance functions to build several measures of standard of achievement in various wellbeing dimensions, and an output distance function to transform those achievement levels into a scalar measure of individual well-being. ${ }^{5}$

\section{Estimating the Level of Achievement in a Given Dimension of Well-Being}

In order to estimate the level of achievement in a dimension we will use input distance functions. In a slight abuse of notation, think of the input (x) and output $(\mathbf{y})$ vectors as the input vector in the production of achievement levels in the various dimensions of well-being and the vector of achievements levels, respectively. Then an individual's endowment of inputs and levels of achievement are denoted by the pair $\left(\mathbf{x}^{i}, \mathbf{y}^{i}\right), i=1, \ldots l$, I being the number of individuals.

The standard of achievement SA may then be estimated using a Malmquist input quantity index so that:

\footnotetext{
${ }^{4}$ While I do not attempt to articulate empirically Sen's capability approach in this paper (but see Deutsch et al., 2003 for a first attempt), it should be obvious that the whole empirical strategy and exercise are inspired by the structure of Sen's approach to well-being.

5 In analysing well-being in poor countries using Sen's capability approach (1980, 1985), Dasgupta (1990) interprets resources and functionings as inputs and outputs in a household production sense.
} 


$$
\mathrm{SA}\left(\mathbf{y}, \mathbf{x}^{\mathrm{s}}, \mathbf{x}^{\mathrm{t}}\right)=\mathrm{D}_{\text {in }}\left(\mathbf{x}^{\mathrm{s}}, \mathbf{y}\right) / \mathrm{D}_{\text {in }}\left(\mathbf{x}^{\mathrm{t}}, \mathbf{y}\right)
$$

where $\mathbf{x}^{\mathrm{s}}$ and $\mathbf{x}^{t}$ are two different input vectors and $D_{\text {in }}$ is an input distance function. The idea behind the Malmquist index is to provide a reference set against which to judge the relative magnitudes of the two input vectors. That reference set is the isoquant $I Q(\mathbf{y})$ and the radially farther $\mathbf{x}^{i}$ is from $\mathrm{IQ}(\mathbf{y})$, the higher its standard of achievement, for $\mathbf{x}^{i}$ must be shrunk more to move back onto the reference set IQ(y).

There is, however, a difficulty because the Malmquist index depends generally on $\mathbf{y}$, the choice of which is arbitrary. One could use an approximation of this index such as the Tornquist index, but such an index requires price vectors as well as behavioural assumptions. ${ }^{6}$ Since we do not have prices for inputs we adopt an alternative strategy, and approximate the standard of achievement index, SA, by using only data on individual input vectors. The idea is to get rid of $\mathbf{y}$ by treating all individuals equally and assume that each individual has the same level of achievement: one unit for each of the $M$ dimensions distinguished. Let e represent such a vector of achievements -an Mdimensional vector of ones. Thus, the reference set becomes IQ(e) and bounds the input vectors from below. Individuals with input vectors onto IQ(e) share the lowest level of achievement, with an index value of unity, whereas individuals with large input vectors will then have higher levels of achievement, with index values above unity.

\footnotetext{
${ }^{6}$ This is also the case of other indices that are usually used to approximate the Malmquist index such as the Paasche index, the Laspeyres index or the Fisher index.
} 
To estimate the distance function, define a $(\mathrm{N}-1)$ dimensional vector $\mathrm{z}$ as $z=\left\{z_{j}\right\}=\left\{x_{j} / x_{N}\right\}$ with $j=1, \ldots, N-1$. Then $D_{\text {in }}(e, z)=\left(1 / x_{N}\right) \cdot D_{\text {in }}(e, x)$ and, since $D_{\text {in }}(e, x) \geq 1,{ }^{7}$ we have

$$
\left(1 / X_{N}\right) \leq D_{\text {in }}(e, z)
$$

This implies that we may also write

$$
\left(1 / \mathrm{X}_{\mathrm{N}}\right)=\mathrm{D}_{\text {in }}(\mathrm{e}, \mathrm{z}) \cdot \exp (\varepsilon), \quad \varepsilon \leq 0 .
$$

By assuming that $D_{\text {in }}(e, z)$ has a translog functional form, we have ${ }^{8}$

$$
\ln \left(x_{N}^{-1}\right)=\alpha_{0}+\sum_{j=1}^{N-1} \alpha_{j} \ln z_{j}+\frac{1}{2} \sum_{j=1}^{N-1} \sum_{k=1}^{N-1} \alpha_{j k} \ln z_{j} \ln z_{k}+\varepsilon
$$

Estimates of the coefficients $\alpha_{j}$ and $\alpha_{j k}$ may be obtained using COLS (corrected ordinary least squares) ${ }^{9}$ while the input distance function $D_{\text {in }}\left(e, x^{i}\right)$ for each individual $i$ is provided by the transformation

$$
D_{\text {in }}\left(e, x^{i}\right)=\exp \left\{\max \left(\varepsilon_{i}\right)-\varepsilon_{i}\right\}
$$

This distance will, by definition, be greater than or equal to one (since its logarithm will be non-negative) and will hence indicate by how

\footnotetext{
${ }^{7}$ See above for the properties of the distance functions.

8 To avoid multicollinearity problems with the translog specification covariates that show a correlation higher than $70 \%$ were dropped.

${ }^{9}$ For further information on COLS and other possible estimation methods, see Greene (1980) or Appendix A3 in Deutsch et al. (2003). Arguably, the translog specification may suffer from endogeneity problems. These problems arise because of the cross-product terms, $\sum_{j=1}^{N-1} \sum_{k=1}^{N-1} \alpha_{j k} \ln z_{j} \ln z_{k}$. If the latter did not contribute much to the explanatory power of the model, one could drop them and get rid of the endogeneity problem. However, this is not our case. Alternatively, nonlinear instrumental variable estimation could be performed (to instrument the normalising variable, $x_{N}$ ). The problem usually faced is the lack of good instruments for every one of the translog models. Therefore, endogeneity problems constitute an econometric weakness of the procedure that normally cannot be confronted satisfactorily.
} 
much an individual's resources must be scaled back in order to reach the isoquant $\mathrm{IQ}(\mathbf{e})$. This procedure guarantees that all input vectors lie on or above the resource frontier IQ(e). The level of achievement for individual $i$ will then be obtained by dividing $D_{\text {in }}\left(\mathbf{e}, \mathbf{z}^{\mathrm{i}}\right)$ by the minimum observed distance value -which by definition equals 1 .

\section{Estimating the Overall Level of I ndividual Well-Being}

The overall level of Well-Being, WB, may be derived and estimated in a similar manner. Now, though, instead of an input distance function we use an output distance function. A theoretical index of Well-Being, WB, may be estimated using a Bergson-Moorsteen output quantity index

$$
W B\left(\mathbf{x}, \mathbf{y}^{\mathrm{s}}, \mathbf{y}^{\mathrm{t}}\right)=\mathrm{D}_{\text {out }}\left(\mathbf{x}, \mathbf{y}^{\mathrm{s}}\right) / \mathrm{D}_{\text {out }}\left(\mathbf{x}, \mathbf{y}^{\mathrm{t}}\right)
$$

where $\mathbf{y}^{\mathbf{s}}$ and $\mathbf{y}^{\mathrm{t}}$ are two achievement vectors and $\mathbf{x}$ is an input vector. Clearly, the further inside the output set $P(\mathbf{x})$ an achievement vector is, the more it must be radially expanded in order to meet the standard and the lower the corresponding well-being.

Here also the problem is to choose a reference vector, in this case an input vector $\mathbf{x}$. We will, this time, define a $\mathrm{N}$-dimensional vector $\mathbf{e}$ of ones. That is, we will assume that each individual is endowed with one unit of each input. This implies that we define a reference set $\operatorname{PPF}(\mathbf{e})$ which bounds from above the observed achievements of the various individuals. If an individual has a vector of achievements that places her on the frontier of $\mathrm{P}(\mathbf{e})$, this implies that she has the maximum level of well-being and, hence, an output index of unity. Individuals with smaller achievement levels will have a lower level of well-being and, hence, index values below unity. As before, note that this index is 
independent of the units in which the achievement levels are measured.

To estimate the output distance functions we proceed as in the input distance case. We assume a translog functional form

$$
\ln \left(y_{M}^{-1}\right)=\beta_{0}+\sum_{f=1}^{M-1} \beta_{f} \ln v_{f}+\frac{1}{2} \sum_{f=1}^{M-1} \sum_{h=1}^{M-1} \beta_{f h} \ln v_{f} \ln v_{h}+\varepsilon
$$

where $v_{f}=\left(y_{f} / y_{M}\right), f=1, \ldots, M-1$. The (modified) residuals, which are then derived from COLS, provide output distance functions for each individual by means of the transformation

$$
D_{\text {out }}\left(\mathbf{e}, \mathbf{y}^{\mathrm{i}}\right)=\exp \left\{\min \left(\varepsilon_{\mathrm{i}}\right)-\varepsilon_{\mathrm{l}}\right\}
$$

This distance will by definition be smaller than or equal to one (since its logarithm will be non-positive and at most equal to zero) so that all individual achievement vectors will lie on or beneath the achievement frontier corresponding to $\mathrm{P}(\mathbf{e})$. Hence, the output distance function $D_{\text {out }}\left(\mathbf{e}, \mathbf{y}^{\mathrm{i}}\right)$ gives the maximum amount by which individual achievement levels vectors must be radially scaled up in order to reach the achievement frontier. Finally, a well-being index $\operatorname{WB}\left(\mathbf{x}, \mathbf{y}^{\mathbf{s}}, \mathbf{y}^{\mathbf{t}}\right)$ is obtained by dividing all the output distance functions by the maximum observed distance - by definition equal to 1 .

\section{Short Review of Previous Work}

Some ten years ago, Lovell et al. (1994) offered "a new view of inequality in Australia". Such new view had two major features. The first one was the novelty of their approach which, as explained in the previous section, employs distance functions to approximate the 
measurement of individual standard of living and quality of life. The second one was defining their two measures of interest, standard of living and quality of life, in line with Sen's capability approach something that few studies had previously attempted. Thus, standard of living is defined from a set of economic resources or commodities, whereas quality of life gets measured by an index of individual functionings -being thus close to our index of Well-Being.

Using data from the Australian Standard of Living Study, a national representative survey conducted in 1987, Lovell et al. (1994) find evidence of very little inequality in the standard of living and quality of life. The Gini coefficient of the standard of living is 0.009 , while the Gini of post-tax equivalent income is 0.193 , more than twenty times bigger. Since the standard of living index includes other resources in addition to income, the authors conclude that the additional resources "prove to be a great equalizer, a finding we find encouraging". Their results also indicate that inequality in the standard of living understates inequality in the quality of life -that throws a Gini of 0.048. That is, resources are more equally distributed than functionings, which suggests that not all individuals are equally proficient in transforming resources into functionings. Actually, the lack of correlation between these two dimensions clearly indicates that possession of resources does not guarantee the enjoyment of functionings. This efficiency in transforming resources into functionings gets measured by a transformation efficiency index which is highly correlated with the quality of life index - they both use output distance functions. 
The few studies that estimate standard of living and quality of life indices following Lovell et al. (1994) and using data for different countries, corroborate the main results found with Australian data: very low levels of inequality in standard of living and quality of life; at most very weak relationship between the two concepts; and close relationship between the transformation efficiency index and the quality of life index (see Delhausse, 1996; Deutsch, Silber and Yacouel, 2000, and Deutsch, Ramos and Silber, 2003). ${ }^{10}$

Of course, with such high levels of concentration in both the standard of living and the quality of life indices, poverty considerations are not easily approached. When the poverty line is set at usual thresholds (about $60 \%$ of the median), there is hardly any poverty in the distribution. Thus, studies typically use thresholds that are much closer to the median value. Only then the comparison of different poverty indicators yields some interesting and meaningful results. For instance, using data for Great Britain in 1997, Deutsch, Ramos and Silber (2003) find that only $22 \%$ of those who are poor according to the standard of living are also poor according to the quality of life, and only around $16 \%$ of those who are poor according to the conventional equivalent income measure are also poor according to the measures of standard of living and quality of life.

Besides these studies on quality of life, two additional papers have used Lovell et al.'s methodology to investigate the effects of religiousness and to obtain estimates of human development. Deutsch and Silber (1999) look at the effect of religiousness on the efficiency

\footnotetext{
10 Delhausse (1996) uses French data (Etude des Conditions de Vie) for 1986-87; Deutsch, Silber and Yacouel (2000) use Israeli time-survey data for 1992-93; Deutsch, Ramos and Silber (2003) use the British Household Panel Survey (BHPS) for 1997.
} 
with which individuals are able to transform resources into well-being, as measured by a quality-of-life-type index. Their findings suggest that, on average, non-religious individuals enjoy greater levels of resource-based standard of living. However, religious individuals enjoy higher levels of well-being, and thus are more efficient in transforming resources into well-being.

Finally, Ramos and Silber (2005), use Lovell et al.'s methodology to translate empirically some categorizations of human development. They compare the estimates of human development obtained on the basis of Sen's (1985) capability approach, Narayan et al.'s (2000) dimensions of well-being, Cummins (1996) domains of life satisfaction and Allardt's (1993) comparative Scandinavian welfare study, and obtain a great empirical resemblance between the different approaches: relative high levels of achievement in most dimensions and of well-being, and low levels of inequality of well-being.

\section{THE DATA}

The data used in the empirical exercise come from the Panel de Desigualtats a Catalunya $(\mathrm{PaD})$, a national representative survey conducted in 2001 to feed the study of social inequalities in Catalonia. Thus, it offers a rather rich set of information to attempt the estimation of well-being. Notwithstanding this, it suffers from the same drawbacks than most surveys. Perhaps the most relevant disadvantage for our analysis is that it does not include individuals not living in private households (e.g. living in institutions, on the street or do not having stable residency), who are most likely the neediest individuals of all. 
The sample used in this study consists of 3276 individuals who provide valid answers to the questions relevant to our investigation. From the information available in the $\mathrm{PaD}$ we define 6 dimensions of well-being: Health related, being able to provide good education, work-life balance, housing conditions, social life and networking, economic status and working conditions. Arguably most of the seven considered dimensions should be relevant to assess well-being both in developing and developed countries - as it is the case of the empirical illustration of section 5-, being perhaps work-life balance the dimension which may not raise so much concerned when analysing a developing country. All these dimensions have been evaluated on the basis of a reduced number of variables -though main conclusions are robust to dimensions being evaluated by means of one variable only. It is important to note that most variables are qualitative, either categorical or dichotomous, and include both subjective and objective information -see Appendix A for a complete list and main characteristics of these variables.

The health related dimension (or functioning) is evaluated on the basis of some subjective questions such as the self-assessed health status or an index that assesses the extent to which health hinders doing certain basic activities, ${ }^{11}$ and two objective variables identifying physical and psychological disability. If education plays such a central role in our lives as economic theory predicts, the possibility to provide good education to one's offsprings should be a central dimension to well-being. However, this interesting and important dimension is rarely included in empirical studies - possibly due to the lack of information.

\footnotetext{
11 This index is a summated rating scale of six categorical variables - see Appendix A for more information on these 6 variables. Scale reliability was assessed using a coefficient alpha, whose estimated value $(0.96)$ is well above the widely used rule of thumb of 0.70 .
} 
Here, it has been appraised by means of three subjective indicators capturing important aspects of this dimension: the satisfaction with children's education, whether the quarter of residency is a good one to bring up children, and whether a school had to ever be discarded because of its cost. The information concerning work-life balance comes from answers to two questions about the satisfaction with one's amount of leisure time and with that spent with children, and from another more objective indicator identifying the individuals who had to quit their job to take care of relatives. Housing conditions are once again depicted relying on objective as well as subjective information. On the objective side there is an indicator as whether there are major deficiencies in the dwelling which the individual cannot afford repairing, and a crowding indicator which weighs the dwellings size with the household size and composition. The subjective questions report information on living in the desired dwelling and neighbourhood, and not being able to afford a comfortable house. Social Life and Networks has been appraised by means of a subjective ranking showing the level of satisfaction about one's social life and a set of three variables indicating if anyone would help in front of certain problems. To assess the economic status I have deliberately avoided using any direct measure of income or wealth, and thus have rather opted for an assessment of economic status based on subjective perceptions about own's financial situation - which show a weak/moderate correlation with the more objective income and wealth indicators; see on. The items considered include the possibility of making ends meet, the amount saved in the previous year (measured in terms of the number of days that the individual could live out of those savings), a variable that measures whether there have been delays in the payment of loans, mortgage, utilities' bills or shopping, 
and a deprivation index that brings together eight variables capturing the impossibility of affording rather basic items. ${ }^{12}$

\section{Empi ri cal Results: Esti mati ng Well-Being in Cataloni a}

As explained in Section 2, I use a two stage procedure to estimate individual well-being in Catalonia. In the first stage I estimate individual achievement levels for the 6 dimensions of well-being by means of input distance functions, using the information contained in Appendix A -and briefly described in the previous section. These dimensions are then used in the second stage to finally estimate the overall level of individual well-being using an output distance function.

\section{The Distribution of Well-Being Dimensions and of Overall Well- Being}

Bearing in mind that the distribution of the overall index of well-being takes on values in the interval $[0,1]$, where zero denotes minimum level of well-being and one complete attainment, the results in Table 1 suggest that, on average, Catalans enjoy moderate levels of well-being (0.52). A look at the mean values for the many constituents of wellbeing reveals that the health related dimension scores highest while individuals do not achieve good attainment levels in economic status and in providing good education to their children. It is interesting to notice that despite the more socialising character typically attributed to the Mediterranean, Catalans do not fare very well in the dimension capturing the social life and networking aspects of well-being. ${ }^{13}$

\footnotetext{
${ }^{12}$ This index is a summated rating scale of six categorical variables - see Appendix A for more information on these 8 variables. Scale reliability was assessed using a coefficient alpha, whose estimated value (0.78) is greater than the widely used rule of thumb of 0.70.

${ }^{13}$ Ramos and Silber (2005) for Great Britain and Lelli (2001) for Belgium also find high scores for health related dimensions. Unlike my results for Catalonia, however, these two studies also find high achievement levels in material and social dimensions.
} 
As in all previous studies that use distance functions, differences in individual well-being appear to be very small -Gini coefficients are shown in the last column of Table $1 .{ }^{14}$ The differences are however somewhat more important if ones looks at some of the dimensions see Figure 3 for density estimates of the six dimensions and the index of well-being. As a whole, the differences in the various constituent dimensions of well-being seem to compensate each other yielding a rather equally distributed overall index of well-being. Such low degrees of inequality are surely a consequence of the qualitative nature of most of our variables, and of the two aggregating stages required to arrive at the overall index of well-being.

All these inequality figures cannot be taken at face value. Clearly, the inequality displayed in the distribution of the overall index of wellbeing cannot be directly compared to the typically observed differences in equivalent income -e.g. the Gini for Catalonia in 2000 amounts to 0.32 . However, as it should be made clear below, policy implications can still be drawn from our analysis, especially from simple multivariate analysis.

Sen's quotation at the beginning of the paper clearly illustrates the multidimensional nature of well-being. Now, as suggested by the quotation, an empirical assessment of the different dimensions only makes sense if they are somewhat independent from one another. Hence the analysis of simple correlations between the constituent dimensions of well-being should be of interest. From a policy viewpoint, strong correlation between dimensions implies dependency

${ }^{14}$ Estimates for other inequality indices, such as the Generalized Entropy Family or Atkinson indices, provide a very similar story and are available from the author upon request. 
between well-being constituent elements. In other words, doing worse in one dimension not only affects one's position in that dimension but also in other aspects of well-being, which should then raise higher concerns for policy making. Additionally, from a methodological perspective, very strong correlations between constituent elements do not provide grounds that vindicate a multidimensional assessment of well-being. The weak correlations between the various dimensions displayed in Table 2, should be then good news. In terms of policy, they imply that one's standing in one distribution does not determine one's standing in any other distribution. And from a methodological point of view they indicate that our concern about the different dimensions of well-being makes sense, at least for the case of Catalonia!

Furthermore, all well-being dimensions are rather weakly correlated with equivalent income, which indicates that economic resources do not necessarily lead to higher achievement levels in the different dimensions of well-being, or alternatively, that individuals may enjoy high levels of achievement in any given well-being dimension without having much (equivalent) income. ${ }^{15}$ Note also that most correlations have the expected sign. For instance, the positive correlation with the health related dimension is in line with the positive effect of income on health status, reported in the health economics literature. Likewise, income is positively correlated with another two resource-relateddimensions: housing conditions and economic status. The small but positive correlation between income and the dimension capturing the perception about the education being provided to one's children may be a reflection of the education system in Catalonia, where state and

15 To equivalize income I use the so-called modified OECD equivalence scale that assigns a weight of 1 to the first adult, of 0.5 to the other adults in the household and of 0.3 to children. 
private-run-highly-subsidized schools gather a great majority of all pupils.

Like its constituent dimensions, overall well-being shows a rather weak correlation with equivalent income. The important lesson one should learn from these weak correlations between income and (dimensions of) well-being is that studies of economic and social development that focus only on income related indicators clearly miss important aspects of the quality of life. This should definitely provide support for the efforts made by the UNDP to capture as many dimensions as possible in its human development indicators.

On the whole, the results I obtain for Catalonia in 2000 are very much in line with those obtained in previous studies which apply the same methodology to other countries - see Section 3. Next, I use standard multivariate analysis to investigate what socio-economic and personal characteristics relate to higher achievement levels in the different dimensions as well as to higher overall well-being.

\section{Multivariate analysis of Well-being}

The OLS regressions include some usual socio-economic characteristics, namely age, education, sex, marital status, region of residence, number of individuals working in the household and labour market situation; but also some covariates that are rarely used in multivariate analyses of individual well-being, such as information as to whether any event has shaken one's life in the previous five years, living next to relatives, national identity feeling or dwelling ownership status - summary statistics and definition of all covariates can be found in Appendix B. 
The coefficient estimates for the well-being index are shown in the first column of Table 3. Age shows the usual inverse $U$-shape effect on well-being that resembles age-earnings or age-income profiles: wellbeing increases until age 41 , decreasing thereafter. Not unexpectedly, education is also positively correlated to well-being. Thus, more education not only provides, on average, higher income levels but also higher well-being. The data also show a slight gender bias in favour of men. The labour market situation of individuals appears not to bear any effect on overall well-being, with the notable exception of the retired, who surprisingly enjoy higher levels of well-being.

The set of dummies capturing the effect of the type of dwelling ownership clearly shows that renting is an inferior option in Catalonia, left mostly to those who cannot afford buying. This adds further evidence to recent findings obtained in the deprivation literature (Ayllón, Mercader and Ramos, 2004). As it has been long established in the psychology literature, the negative sign of the control variable life shaking events demonstrates that circumstances matter. ${ }^{16}$ Living close to relatives increases the well-being of individuals, which is consistent with the Spanish family-centred Southern European welfare regime (Esping-Andersen, 1990).

The last issue of my concern relates to the effect on well-being of selfdefined national identity (i.e. either Catalan or Spanish). Because of its explanatory power identity has been adopted as a central concept by

\footnotetext{
${ }^{16}$ The psychology literature recognises that self-reported measures are a reflection of at least four elements: circumstances, aspirations, comparison with others, and a person's baseline happiness (Warr, 1980; cited in Blanchflower and Oswald, 2004). Since our well-being index derives from many self-reported variables, it seems reasonable to expect these four factors to affect somewhat our estimated well-being measure.
} 
many social scientists (Akerlof and Kranton, 2000), and the very few economists who have brought identity into economics, have successfully shown that identity may be crucial in explaining some economic behaviour not accounted for by previous economic models. ${ }^{17}$ Catalonia, an autonomous community within Spain, presents enough distinctive features as for identity to be an important explanatory factor for many economic outcomes, and certainly so, for individual well-being. ${ }^{18}$ My findings suggest that individuals who report 'feeling Catalan', as opposed to 'Spanish', enjoy higher levels of well-being. Note that substituting identity with a language variable (identifying who uses Catalan or Spanish as first language) in the regression does not change the outcome: Catalan speakers enjoy higher well-being levels. This finding is in line with the positive effect that the knowledge of the Catalan language, an important constituent of identity, appears to exert on individual labour market performance as measured by employment probabilities (Rendón, 2005).

Given the many documented advantages of marriage, it is somehow puzzling to find that that marriage has no effect on individual wellbeing. ${ }^{19}$ Also, the number of employed individuals in the household,

\footnotetext{
17 Probably, the most influential contribution is the recent paper by Akerlof and Kranton (2000), who incorporate identity into a general model of behaviour and then demonstrate how identity influences economic outcomes. See also references therein.

18 Perhaps the most salient features are (i) a demographic composition where Spanish immigrants (and their descendants, mostly second or third generations) represent a considerable share of the population living in Catalonia due to massive immigration flows from the rest of Spain during the sixties; (ii) an own language, Catalan, which is very often seen as the key element to preserving the national identity, and which now shares co-officiality with Spanish, after having been aggrieved during Franco's dictatorship, up to 1975; (iii) Spanish ruling of Catalan institutions for many centuries, including the largest part of the XX century, and most notably during Franco's dictatorship, which has surely contributed to the birth, expansion and justification of strong nationalist political parties which have governed the nation since democracy was re-established in Spain in 1978.

19 Marriage has been found to have positive effects both on reported levels of happiness (Myers 1999; Stutzer and Frey 2003; Blanchflower and Oswald 2004) and health (Ross et al. 1990; Waite and Gallagher 2000; Wilson and Oswald 2002; Ribar 2004). In addition, a male
} 
which should mean higher economic resources, shows no relationship with well-being -according to an F-test on joint significance.

Table 3 also displays the estimates of the OLS regressions on the six dimensions of well-being. A detailed analysis is beyond the scope of this paper. Thus, next we only discuss the most interesting findings. As expected, education seems to be fairly important for all six dimensions - behaving in a rather monotonic fashion. Contrary to the evidence on the positive effects of marriage on some outcomes such as happiness and health, the estimates of Table 3 suggest that civil status (and marriage) does not matter much; but with some few exceptions: widow(er)s seem to suffer more health related problems and also fare worse when it comes to social life and networking but enjoy better housing conditions; ${ }^{20}$ singles and divorced have lower economic status, and singles show better work-life balance.

Being employed is related to better housing conditions but also to worse work-life balance (no wonder why), whereas the unemployed have a less satisfactory social life and also have a worse economic situation. As far as dwelling ownership is concerned, it is important to point out that renters suffer the worse housing conditions. ${ }^{21}$ Having recently experienced a life shaking event affects negatively economic status, but does not appear to have any bearing on other dimensions, such as social life, for which an impact could be expected.

marriage premium is a common finding in wage equations, indicating that marriage is associated with higher wages for men (Bardasi and Taylor, 2005).

${ }^{20}$ The somewhat surprising finding that widow(er)s enjoy better housing conditions (Ayllón et al. (2004) find the opposite in an analysis of deprivation for Catalonia using the same data) may be partly explained by high scores in the crowding index $\left(68 \mathrm{~m}^{2}, 15 \mathrm{~m}^{2}\right.$ higher than the sample mean) -for they typically live alone. Lelli (2001) ascribes the same unusual finding to the "adaptive preferences of the elderly constituting this social group".

${ }^{21}$ In their study on poverty and deprivation in Catalonia, Ayllón et al. (2004) also find that renters suffer from important housing deprivation problems. 
The self-reported national identity plays a role in half of the dimensions. Those who report being Catalan (be it at the same level as Spanish or Catalan only) enjoy better social life, housing conditions and economic status. These findings, however, by no means imply any degree of segregation between the two groups. Finally, having relatives living close by also has a positive effect on the above mentioned dimensions.

\section{Well-being Poverty}

With such a compact well-being distribution we are bound to find very low poverty (as measured by the head count). Figure 4 shows the exponential relationship between the head count measure and the poverty line. The proportion of poor when we use the poverty line typically employed in the income space (i.e. $60 \%$ of the median) is only 1.7 , whereas setting the poverty line at $80 \%$ of the median yields a head count of 9.9 .

What percentage of the population are both well-being and income poor? What proportion of the income poor manage to escape poverty in the well-being space? And how many are also poor according to their well-being? In order to provide answers to all this policy relevant questions, we follow the deprivation literature, ${ }^{22}$ and define well-being poverty as the same percentage of the population found poor according to equivalent income, i.e. $18.4 \%$ of the population. We find that only $5 \%$ of the Catalan population are poor according to both income and well-being indicators. Two thirds of income poor manage

\footnotetext{
22 See, inter alia, Nolan and Whelan (1996), Martínez and Ruiz-Huerta (1999), Ayllón,
} Mercader and Ramos (2004). 
to escape well-being poverty, which means that only one third of income poor are also well-being poor.

To explore the characteristics of the well-being poor Table 4 shows estimated logit marginal effects on poverty using the same specification as in the multivariate analyses above. Not surprisingly, many of the covariates that showed a relationship with the well-being index also show an effect on the probability of belonging to the lowest $18.4 \%$ of the well-being distribution, i.e of being well-being poor. In other words, the logit results of Table 4 are very similar to our previous OLS results of Table 3. For instance, higher levels of education are associated to lower poverty risks. However, there are two differences worth pointing out. First, gender does not appear to condition the poverty risk, and second, divorced and separated individuals face higher risks of well-being poverty.

\section{POLI CY I MPLI CATIONS}

As promised above, our distance function based multidimensional analysis on individual well-being is able to bring out several policy relevant aspects, in spite of the rather equal distributions that it yields.

First and foremost, our empirical analysis vindicates, once again, the necessity to take due account of as many of the many dimensions of well-being as possible when assessing individual well-being and how it is distributed in the population. This is not a new recommendation, but rather the opposite. However, it is one that is still important making, since most efforts in economics are still based on or directed to the study of resource-driven unidimensional measures of well-being. 
The previous recommendation is partly grounded on the weak relationship found between well-being and its constituent dimensions and equivalent income. However, such weak relationship between well-being and current income also applies to previous income changes (0.114) and expected income changes (0.106), self-reported measures of income satisfaction (0.318), and even self-reported indicators of life satisfaction (0.193). Why should our indicator of overall well-being be very different to the self-reported measures of life satisfaction or happiness? And why should not we instead use simple categorical variables eliciting information of life satisfaction or happiness? It appears reasonable to believe that when answering a life satisfaction or happiness survey question, that is, when assessing one's overall well-being, individuals do not consider, and thus do not incorporate, information on all possible dimensions of life. Psychologists draw a clear distinction between the well-being as a whole (named contextfree) and the well-being related to a single dimension of life (contextspecific). Our well-being indicator summarises the subjective assessment on different dimensions of life, and thus builds on many context-specific well-beings which are not entirely subjective accounts but which also incorporate objective information. By doing so, we contest the usage of the very subjective theoretical construct of utility -which could perhaps be approximated by some measure of happiness? - for policy purposes, as already indicated by Sen (1980), and differentiate from recent literature which identifies (or confounds?) happiness with well-being (e.g. Blanchflower and Oswald, 2004) -or should policy makers really care for the expensive tastes of some individuals? 
Thus, contrary to the context-free and subjective indicators of life satisfaction or happiness, our ultimate goal is to obtain a richer or more complete and not entirely subjective account of people's wellbeing, which, in accordance to Sen's capability approach, we consider it to be a better indicator for policy purposes.

\section{Concluding Comments}

This paper shows how distance functions, a tool typically employed in production economics to measure the distance between a set of inputs and a set of outputs, can be employed to approximate a composite multidimensional measure of well-being. It also illustrates how to implement the methodology originally put forth by Lovell et al. (1994), using new data originally collected to foster the study of social inequalities in Catalonia.

The empirical exercise for Catalonia provides (additional) support to the multidimensional approach to poverty and well-being, as opposed to the studies that still understand well-being as a sole function of income. Our overall index of well being, as well as all its constituents, is weakly related to actual income, as well as to past and expected income changes. It is also very loosely related to other entirely subjective and direct appraisals such as life or income satisfaction. This, we believe it is due to two factors: the many dimensions taken into account by our measure of well-being and the mix of objective and subjective information used to estimate the level of achievement in the various dimensions. Standard multivariate analysis helps reassure that our well-being index makes sense (e.g. we find inverse U-shape age profiles or a positive relationship with education), but also throws some results that might have been difficult to predict. For 
instance, national identity bears on individual well-being. However, marital status or labour market situation do not appear to have any significant effect, with the notable exception of the retired, who surprisingly enjoy higher levels of well-being. Not surprisingly, these same covariates are also found to be related to the risk of falling into poverty in the well-being space.

On theoretical grounds, using distance functions to build a composite index with the information of the many dimensions of well-being looks like an attractive idea. And, indeed, such a well-being index is a promising candidate that will surely deserve further attention in future research. However, when it comes to empirical implementation Lovell et al.'s methodology suffers from a major drawback: it yields very equal distributions -far more than, say, typical distributions of income - which, hence, display exceedingly low levels of poverty however measured. As argued elsewhere (Ramos and Silber, 2005) such high degrees of concentration are probably a consequence of the qualitative nature of the data of the variables typically employed in multidimensional studies of well-being, and of the two aggregating stages required to arrive at the overall index of well-being.

As the previous studies reviewed in Section 3 show, the distance function based methodology has proved useful to empirically appraise and compare different concepts of human development (Ramos and Silber, 2005) or to evaluate the effect of religion on the transformation of resources into well-being (Deutsch and Silber, 1999). Notwithstanding this, as it stands today, Lovell et al.'s methodology does not provide, as yet, an entirely satisfactory answer to the many methodological challenges raised by the multidimensional analysis of 
poverty. Therefore, further developments are required if it is to become a widely used method and not to remain as the ever promising candidate. 


\section{References}

Akerlof, G.A. and R.E. Kranton (2000), "Economics and Identity", Quarterly Journal of Economics, CXV(3): 715-53.

Allardt, E. (1993), “Having, loving, being: An alternative to the Swedish model of welfare research, In M. Nussbaum and A. Sen (eds.), The Quality of Life (pp. 99-94). Clarendon: Oxford.

Ayllón, S., M. Mercader and X. Ramos (2004), "Caracterización de la privación y de la pobreza en Cataluña", DEA Working Paper 04.10, Universitat Autònoma de Barcelona.

Bardasi, E. and M.P. Taylor (2005), "Marriage and Wages" Working Papers of the Institute for Social and Economic Research, paper 20055-1. Colchester: University of Essex.

Blanchflower, D. and A.J. Oswald (2004), "Well being over time in Britain and the USA", J ournal of Public Economics, 88: 1359-1386.

Coelli, T., D.S. Prasada Rao and G.E. Battese (1998), An Introduction to Efficiency and Productivity Analysis, Kluwe Academic Publichers, Boston.

Cummins, R.A. (1996), "Domains of life satisfaction: An attempt to order chaos", Social Indicators Research, 38(3): 303-328.

Dasgupta, P. (1990), Well-Being and the extent of its realization in poor countries", Economic Journal, 100:1-32.

Delhausse, B. (1996), "An attempt at measuring functioning and capabilities", University of Liege, unpublished paper.

Deutsch, J. and J. Silber (1999), "Religion, standard of living and the quality of life“, Bar-Ilan University, unpublished paper. 
Deutsch, J., J. Silber and N. Yacouel (2000), "On the measurement of inequality in the quality of life in Israel", Bar-Ilan University, unpublished paper.

Deutsch, J., X. Ramos and J. Silber (2003), "Poverty and Inequality of Standard of Living and Quality of Life in Great Britain," Advances in Quality-of-Life Theory and Research, J. Sirgy, D. Rahtz and A. C. Samli, editors, Kluwer Academic Publishers, Dordrecht, the Netherlands, pp. 99-128

Esping-Andersen, G. (1990), The Three Worlds of Welfare Capitalisms, Oxford: Oxford University Press.

Greene, W. (1980), "Maximum likelihood estimation of econometric frontier functions", J ournal of Econometrics, 13(1): 27-56.

Lovell C.A.K, S. Richardson , P. Travers and L. Wood (1994), "Resources and Functionings: A New View of Inequality in Australia", in: Eichhorn, W. (ed.), Models and Measurement of Welfare and Inequality, Springer-Verlag, Heidelberg, 1994.

Lelli, S. (2001), “Factor analysis vs. Fuzzy sets theory: Assessing the influence of different techniques on Sen's functioning approach", Public Economics Working Paper Series \#121, Centre for Economic Studies, Katholieke Universiteit Leuven.

Martínez, R. and J. Ruiz-Huerta (1999), “Algunas reflexiones sobre la medición de la pobreza. Una aplicación al caso español", in J.M. Maravall (ed.), III Simposio sobre Igualdad y Distribución de la Renta y la Riqueza. Fundación Argentaria, Madrid.

Myers, D.G. (1999), "Close relationship and quality of life", in D. Kahneman, E. Diener and N. Schwarz (eds) Well-being: The foundations of hedonic psychology, New York: Russell Sage Foundation. 
Narayan, D., R. Chambers, M.K. Shah and P. Petesch (2000), Voices of the Poor. Crying out for Change. New York: Oxford University Press for the World Bank.

Nolan, B. and C.T. Whelan (1996), Resources, Deprivation and Poverty. Clarendon Press, Oxford.

Ramos, X. and J. Silber (2005), "On the application of efficiency analysis to the study of the dimensions of human development", Review of Income and Wealth, 51(2): 285-309.

Rendón, S. (2005), “The Catalan premium: Language and employment in Catalonia", Journal of Population Economics, forthcoming.

Ribar, D. (2004), "What do social scientists know about the benefits of marriage? A review of quantitative methodologies", IZA Discussion paper no. 998.

Ross, C.E., J. Mirowsky and K. Goldsteen (1990), "The impact of family on health: The decade in review", Journal of Marriage and the Family, 52 (4), pp.1059-1078.

Sen A.K. (1980), "Equality of What", in: S. McMurrin (ed.), Tanner Lectures on Human Values, Reprinted in Sen, A. 1982, Cambridge University Press, Cambridge.

Sen A. K. (1982), Choice, Welfare and Measurement, Blackwell, Oxford.

Sen A. K. (1985), Commodities and Capabilities, North Holland, Amsterdam. Reprinted in Oxford University Press, Oxford India Paperbacks, 1999.

Stutzer, A. and B.S. Frey (2003), “Does marriage make people happy, or do happy people get married?", Institute for Empirical Research in Economics, University of Zurich, working paper 143. 
Waite, L.J. and M. Gallagher (2000), The case for marriage: Why married people are happier, healthier and better off financially, New York: Doubleday.

Wilson C.M. and A.J. Oswald (2002), "How does marriage affect physical and psychological health? A survey of the longitudinal evidence", unpublished manuscript, University of Warwick. 
Table 1. Summary Statistics of Well-Being Dimensions and Overall Well-Being

\begin{tabular}{lrrrrr}
\hline \hline & Mean & St. Dev. & Min. & Max. & Gini $^{*}$ \\
\hline Health Related & 21.52 & 1.32 & 1.00 & 45.19 & 2.108 \\
Provide Good Education & 2.38 & 0.36 & 1.00 & 3.99 & 8.194 \\
Work-Life Balance & 7.95 & 2.11 & 1.00 & 11.21 & 14.946 \\
Housing Conditions & 4.91 & 0.96 & 1.00 & 13.69 & 9.576 \\
Social Life and Network & 3.41 & 0.36 & 1.00 & 5.02 & 5.394 \\
Economic Status & 1.85 & 0.18 & 1.00 & 2.36 & 4.799 \\
& & & & & \\
Overall Well-Being & 0.52 & 0.07 & 0.17 & 1.00 & 6.646 \\
Equivalent income & 11290.70 & 6687.05 & 2731.87 & 36060.73 & 31.650 \\
\hline \hline
\end{tabular}

${ }^{*}$ Gini coefficient multiplied by 100

Table 2. Correlations between Well-Being Dimensions, Overall Well-Being \& Income

\begin{tabular}{|c|c|c|c|c|c|c|c|c|}
\hline & HR & PGE & WLB & $\mathrm{HC}$ & SLN & ES & WB & Income \\
\hline Health Related & 1.000 & & & & & & & \\
\hline Provide Good Education & $\begin{array}{r}0.014 \\
(0.583)\end{array}$ & 1.000 & & & & & & \\
\hline Work-Life Balance & $\begin{array}{l}-0.037 \\
(0.029)\end{array}$ & $\begin{array}{c}0.030 \\
(0.264)\end{array}$ & 1.000 & & & & & \\
\hline Housing Conditions & $\begin{array}{c}0.025 \\
(0.139)\end{array}$ & $\begin{array}{c}0.113 \\
(0.000)\end{array}$ & $\begin{array}{c}0.062 \\
(0.000)\end{array}$ & 1.000 & & & & \\
\hline Social Life $\&$ Network & $\begin{array}{l}-0.019 \\
(0.247)\end{array}$ & $\begin{array}{c}0.096 \\
(0.000)\end{array}$ & $\begin{array}{c}0.157 \\
(0.000)\end{array}$ & $\begin{array}{c}0.064 \\
(0.000)\end{array}$ & 1.000 & & & \\
\hline Economic Status & $\begin{array}{c}0.133 \\
(0.000)\end{array}$ & $\begin{array}{c}0.025 \\
(0.206)\end{array}$ & $\begin{array}{l}-0.026 \\
(0.137)\end{array}$ & $\begin{array}{c}0.155 \\
(0.000)\end{array}$ & $\begin{array}{c}0.077 \\
(0.000)\end{array}$ & 1.000 & & \\
\hline Overall Well-Being & $\begin{array}{l}-0.035 \\
(0.043)\end{array}$ & $\begin{array}{c}0.065 \\
(0.020)\end{array}$ & $\begin{array}{c}0.388 \\
(0.000)\end{array}$ & $\begin{array}{c}0.139 \\
(0.000)\end{array}$ & $\begin{array}{c}0.114 \\
(0.000)\end{array}$ & $\begin{array}{c}0.839 \\
(0.000)\end{array}$ & 1.000 & \\
\hline Equivalent income & $\begin{array}{c}0.094 \\
(0.000)\end{array}$ & $\begin{array}{c}0.051 \\
(0.013)\end{array}$ & $\begin{array}{l}-0.097 \\
(0.000)\end{array}$ & $\begin{array}{c}0.208 \\
(0.000)\end{array}$ & $\begin{array}{l}-0.052 \\
(0.003)\end{array}$ & $\begin{array}{c}0.235 \\
(0.000)\end{array}$ & $\begin{array}{c}0.178 \\
(0.000)\end{array}$ & 1.000 \\
\hline
\end{tabular}


Table 3. OLS regressions on Well-Being Dimensions and Overall Well-Being

\begin{tabular}{|c|c|c|c|c|c|c|c|c|c|c|c|c|c|}
\hline Variable & WB & & $\mathrm{HR}$ & & PGE & $\mathrm{HC}$ & & SLN & & ES & & WLB & \\
\hline Age & 0.001 & $* *$ & 0.002 & & 0.008 & 0.013 & $*$ & -0.019 & $* *$ & 0.002 & & -0.004 & \\
\hline Age squared & -0.000 & $* *$ & -0.000 & & -0.000 & -0.000 & & 0.000 & $* *$ & -0.000 & $* *$ & 0.000 & \\
\hline Female & -0.007 & $* *$ & 0.059 & & 0.014 & 0.019 & & -0.007 & & -0.003 & & -0.517 & $* *$ \\
\hline \multicolumn{14}{|l|}{ Education } \\
\hline Primary & 0.019 & $* *$ & 0.234 & $* *$ & $0.113 * *$ & 0.191 & $* *$ & -0.014 & & 0.061 & $* *$ & 0.039 & \\
\hline Secondary & 0.024 & $* *$ & 0.151 & & $0.173 * *$ & 0.339 & $* *$ & -0.052 & $* *$ & 0.076 & $* *$ & -0.041 & \\
\hline University & 0.028 & $* *$ & 0.259 & $* *$ & $0.165 * *$ & 0.437 & $* *$ & -0.073 & $* *$ & 0.085 & $* *$ & 0.268 & $*$ \\
\hline \multicolumn{14}{|l|}{ Civil Status } \\
\hline Single & 0.004 & & -0.108 & & 0.058 & 0.023 & & -0.035 & & -0.023 & $* *$ & 0.564 & $* *$ \\
\hline Divorced \& Separated & -0.008 & & -0.247 & & -0.038 & -0.001 & & 0.022 & & -0.045 & $* *$ & 0.086 & \\
\hline Widow(er) & -0.001 & & -0.475 & $* *$ & 0.086 & 0.350 & $* *$ & -0.066 & $*$ & -0.021 & & -0.220 & \\
\hline \multicolumn{14}{|l|}{ \# employed in $\mathrm{HH}$} \\
\hline One & 0.010 & $*$ & 0.407 & $* *$ & $0.229 * *$ & -0.107 & & -0.023 & & 0.045 & $* *$ & -0.159 & \\
\hline Two & 0.011 & $*$ & 0.263 & & $0.267 * *$ & -0.332 & $* *$ & -0.002 & & 0.039 & $* *$ & -0.010 & \\
\hline More than two & 0.010 & & 0.316 & $* *$ & $0.211 *$ & -0.306 & $* *$ & 0.009 & & 0.035 & $* *$ & 0.118 & \\
\hline \multicolumn{14}{|l|}{ Labour Market Status } \\
\hline Unemployed & -0.004 & & -0.132 & & -0.091 & -0.459 & $* *$ & -0.082 & $* *$ & -0.041 & $*$ & 0.881 & $* *$ \\
\hline Retired & 0.021 & $* *$ & 0.047 & & -0.011 & -0.147 & $*$ & -0.031 & & 0.020 & & 1.401 & $* *$ \\
\hline Inactive & 0.004 & & -0.246 & $* *$ & 0.045 & -0.247 & $* *$ & 0.006 & & -0.017 & & 0.813 & $* *$ \\
\hline \multicolumn{14}{|l|}{ Province } \\
\hline Girona & 0.004 & & 0.260 & $* *$ & 0.033 & 0.175 & $* *$ & 0.004 & & 0.010 & & 0.200 & $* *$ \\
\hline Lleida & 0.005 & & 0.158 & $* *$ & $-0.054 *$ & 0.111 & $* *$ & 0.020 & & 0.022 & $* *$ & -0.044 & \\
\hline Tarragona & -0.007 & $*$ & 0.077 & & $0.056 *$ & 0.103 & $* *$ & -0.028 & & -0.011 & & -0.056 & \\
\hline \multicolumn{14}{|l|}{ Dwelling ownership } \\
\hline Mortgage & -0.001 & & -0.023 & & -0.039 & -0.001 & & -0.015 & & -0.005 & & 0.023 & \\
\hline Renting & -0.022 & $* *$ & -0.008 & & $-0.108 * *$ & -0.425 & $* *$ & -0.075 & $* *$ & -0.073 & $* *$ & 0.189 & \\
\hline Other & -0.003 & & -0.158 & & -0.025 & 0.060 & & -0.027 & & -0.016 & & 0.179 & \\
\hline Life shaking event & -0.023 & $* *$ & -0.024 & & 0.113 & -0.009 & & 0.021 & & -0.061 & $* *$ & -0.256 & \\
\hline
\end{tabular}


Table 3. OLS regressions on Well-Being Dimensions and Overall Well-Being (cont.)

\begin{tabular}{|c|c|c|c|c|c|c|c|}
\hline Variable & WB & $\mathrm{HR}$ & PGE & $\mathrm{HC}$ & SLN & ES & WLB \\
\hline \multicolumn{8}{|l|}{ National I dentity } \\
\hline Equally Catalan \& Spanish & $0.011 * *$ & 0.016 & 0.064 & $0.162 * *$ & $0.091 * *$ & $0.025 * *$ & 0.142 \\
\hline Catalan & $0.012 * *$ & 0.130 & 0.049 & $0.159 * *$ & $0.089 * *$ & $0.030 * *$ & 0.024 \\
\hline Relatives live close by & $0.009 * *$ & 0.047 & $0.072 *$ & $0.173 * *$ & $0.057 * *$ & $0.018 *$ & 0.029 \\
\hline Constant & $0.481 * *$ & $21.024 * *$ & $1.515 * *$ & $4.054 * *$ & $3.800 * *$ & $1.792 * *$ & $7.391 * *$ \\
\hline $\mathrm{R}^{2}$ & 0.072 & 0.050 & 0.080 & 0.113 & 0.045 & 0.150 & 0.153 \\
\hline
\end{tabular}

The omitted dummies are: male, no education, married, no employed in the $\mathrm{HH}$, working, Barcelona, owns house without mortgage, feels Spanish. 
Table 4. Logit marginal effects on Well-Being Poor

\begin{tabular}{lc}
\hline \hline Variable & Marginal Effect \\
\hline Age & $-0.007 * *$ \\
Age squared & $0.000 * *$ \\
Female & 0.022 \\
Education & \\
$\quad$ Primary & $-0.101 * *$ \\
Secondary & $-0.110^{* *}$ \\
University & $-0.122 * *$ \\
Civil Status & \\
Single & -0.004 \\
Divorced \& Separated & $0.113 * *$ \\
Widow(er) & 0.010 \\
\# employed in HH & \\
One & -0.023 \\
Two & -0.026 \\
More than two & -0.028 \\
Labour Market Status & \\
Unemployed & 0.006 \\
Retired & $-0.074 * *$ \\
Inactive & -0.005 \\
Province & \\
Girona & $-0.031 *$ \\
Lleida & $-0.051 * *$ \\
Tarragona & 0.016 \\
Dwelling ownership & \\
Mortgage & 0.033 \\
Renting & $0.112 * *$ \\
Other & -0.025 \\
Life shaking event & \\
National Identity & \\
Equally Catalan \& Spanish & \\
Catalan & $-0.038 * *$ \\
Relatives live close by & $-0.042 * *$ \\
Log pseudolikelihood & \\
\hline Note: $* *$ significant at $5 \% ; *$ significant at & $10 \%$ \\
The omitted dummies are: male, no education, married, \\
no employed in the HH, working, Barcelona, \\
owns house without mortgage, feels Spanish. \\
\hline
\end{tabular}




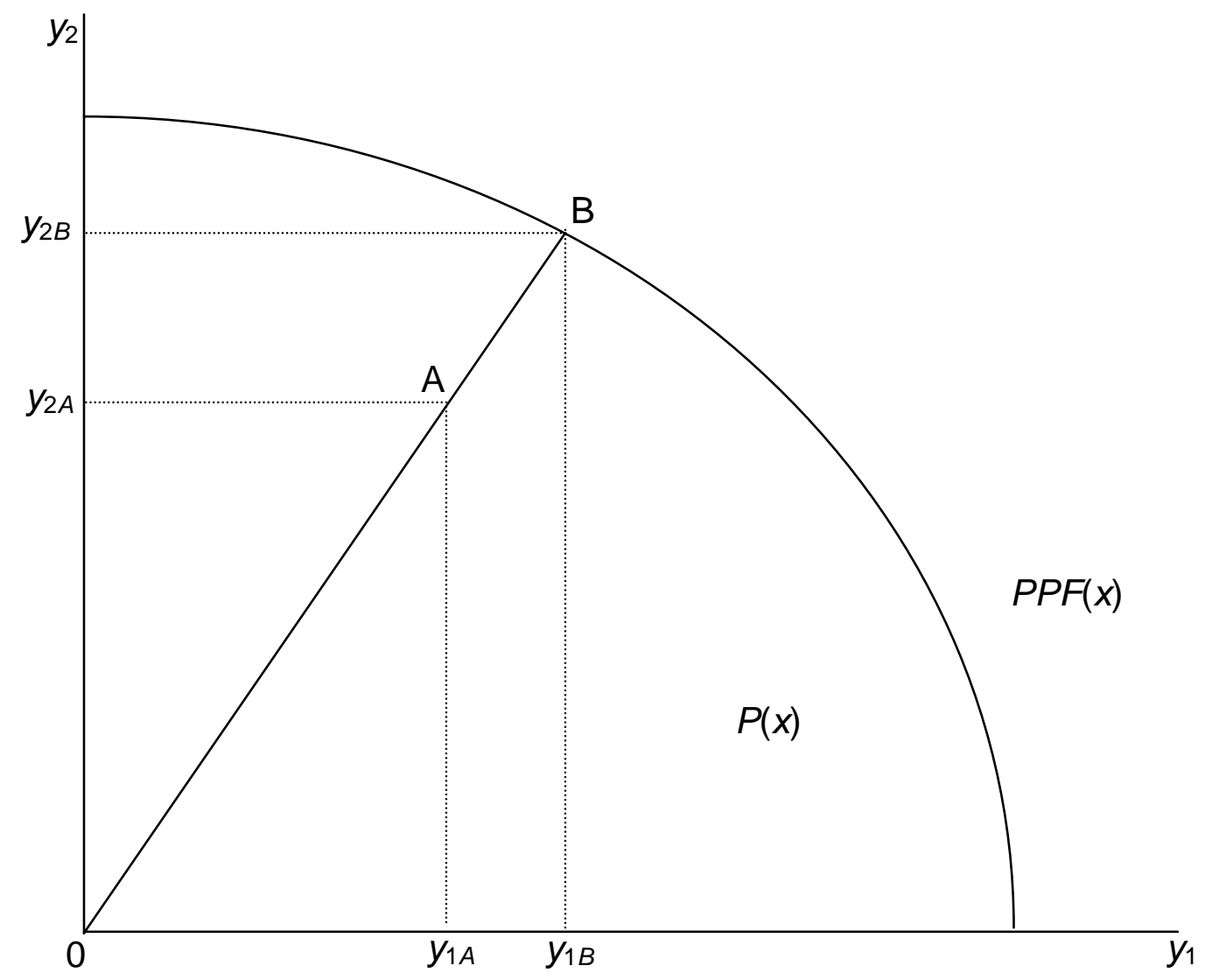

Figure 1. The output distance function 


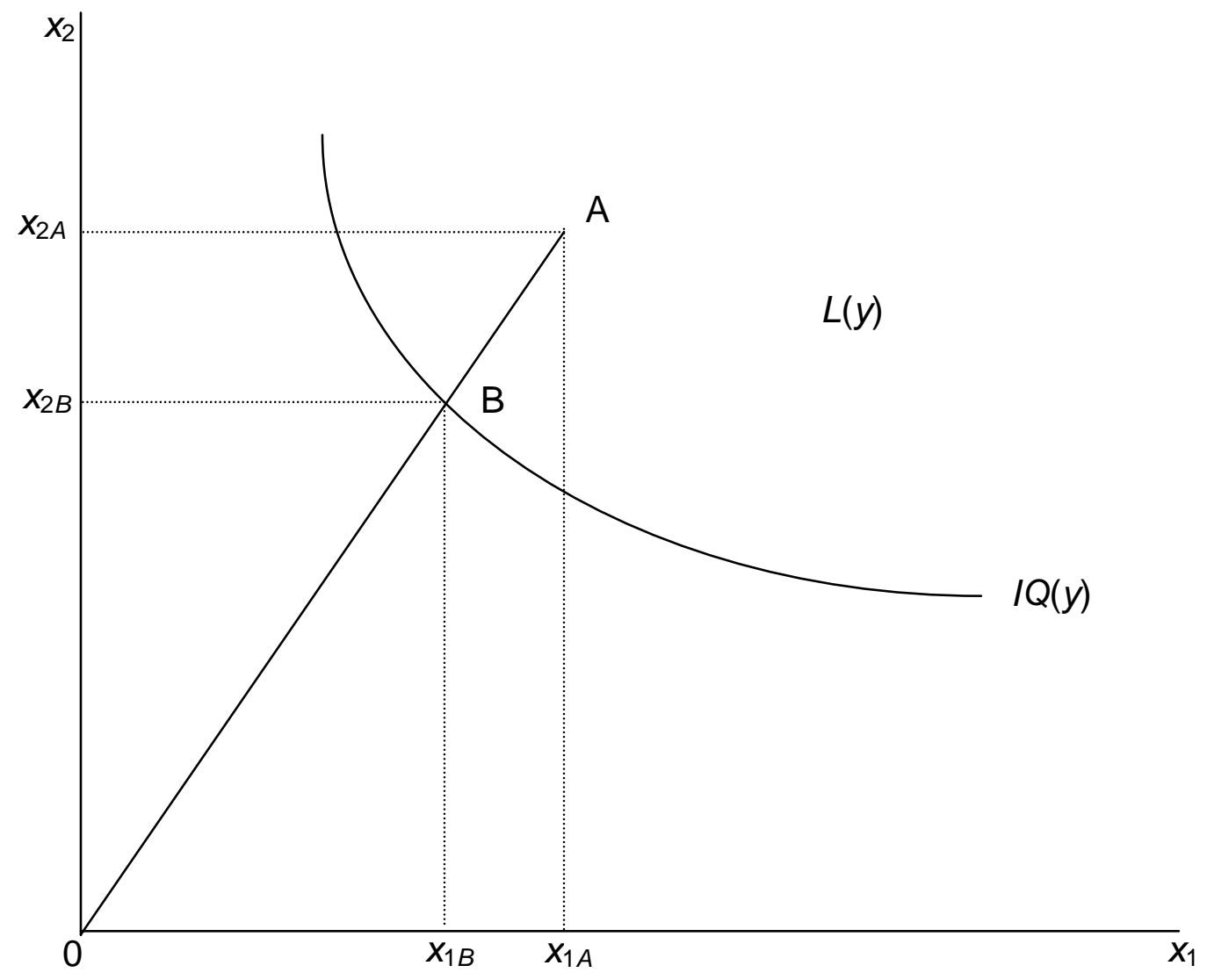

Figure 2. The input distance function 
Estimated Densities of Dimensions and Well-Being
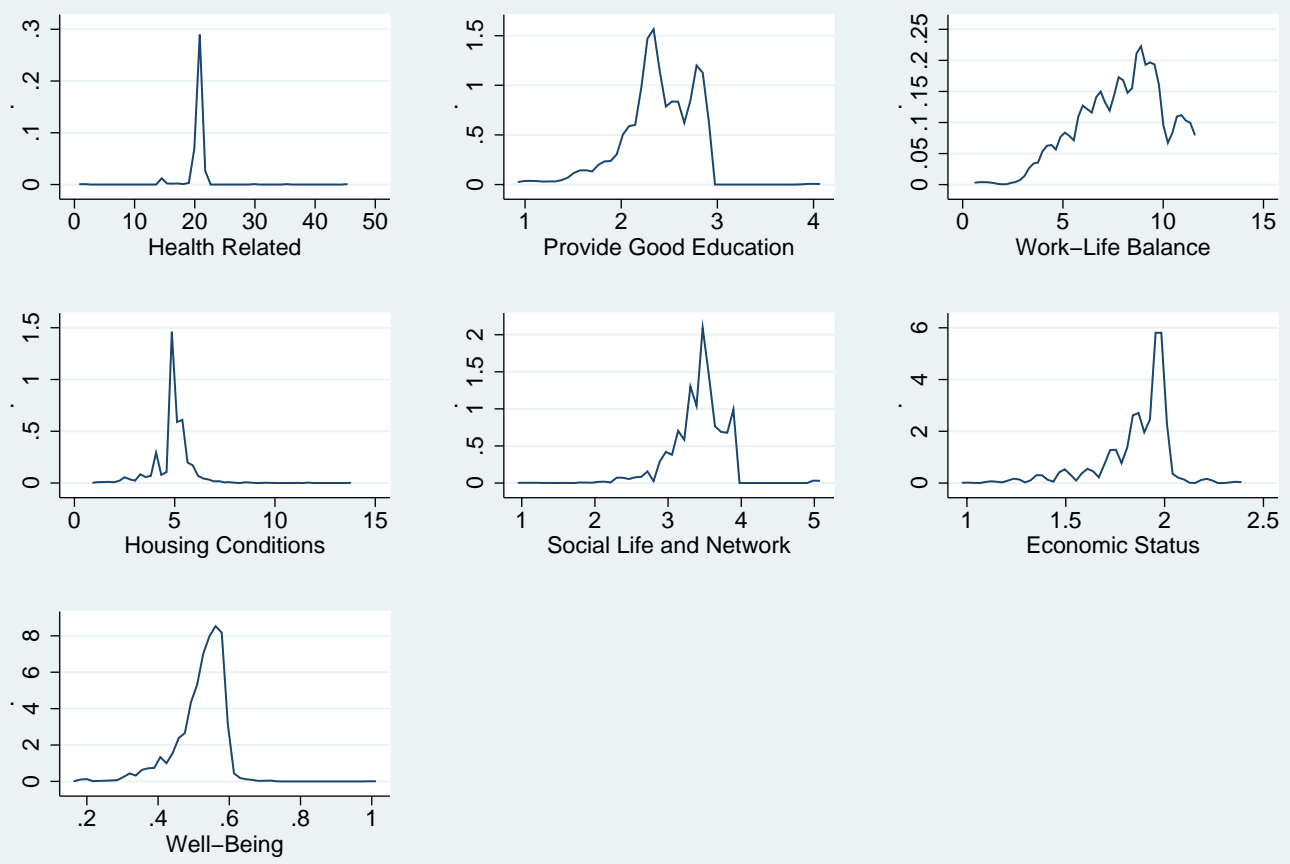

Figure 3. Density estimates of Dimensions and Well-Being

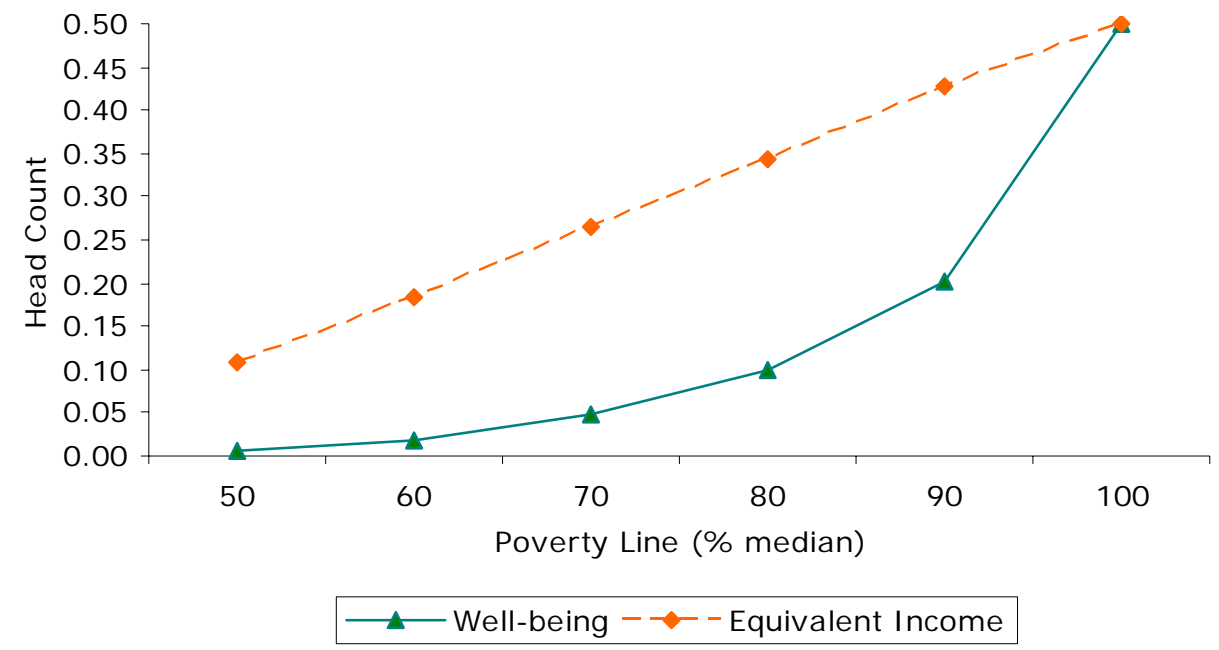

Figure 4. Poverty (Head Count) for various Poverty Line definitions 


\section{Appendi X A. VARI Ables Used to Esti mate the Dimensions}

\begin{tabular}{lll}
\hline \multicolumn{1}{c}{ Indicator Name } & \multicolumn{1}{c}{ Description } & Type of Indicator \\
\hline \multicolumn{2}{c}{ HEALTH RELATED } \\
\hline dificult & Health hinders certain activities ${ }^{23}$ & \\
discf & Physical disability & Summated scale (1-4) \\
discm & Psychological disability & Dichotomous \\
salut10 & Self-assessed health status (1-10) & Dichotomous \\
& & Categorical (10 mod.)
\end{tabular}

PROVIDE GOOD EDUCATION

\begin{tabular}{lll}
\hline sateduf & Satisfaction with children's education & Categorical (10 mod.) \\
bbxfill & Good quarter to bring up children? & Dichotomous \\
cantpayedu & School discarded because of its costs & Dichotomous
\end{tabular}

WORK - LIFE BALANCE

\begin{tabular}{lll}
\hline jbless4rel & Had to quit job to care for relatives & Dichotomous \\
sattll & Satisfaction with amount of leisure time & Categorical (10 mod.) \\
sattllk & Satisfaction with amount of time spent with children & Categorical (10 mod.)
\end{tabular}

HOUSING CONDITIONS

\begin{tabular}{lll}
\hline crowd & Crowding index $\left(\mathrm{m}^{2} /\right.$ equivalence .scale) & Continuous \\
hdef & Housing deficiencies which cannot afford repairing & Dichotomous \\
hhpyflt & Live in desired dwelling & Dichotomous \\
hhpynbh & Reside in desired neighbourhood & Categorical (3 mod.) \\
hcomfi & Live (can afford living) in comfortable house? & Dichotomous
\end{tabular}

SOCIAL LIFE AND NETWORK

\begin{tabular}{|c|c|c|}
\hline satvsoc & Satisfaction with social life & Categorical (10 mod. \\
\hline helpprob & Is there someone who can help if personal problems? & Categorical (3 mod.) \\
\hline helpnoin & Is there someone who can help if financial problems? & Categorical (3 mod.) \\
\hline helprel & Anyone to help if in need to care for relatives or sick? & Categorical (3 mod.) \\
\hline \multicolumn{3}{|c|}{ ECONOMIC STATUS } \\
\hline endsmeet & Possibility of making ends meet & Categorical (5 mod.) \\
\hline diffin & Financial difficulties ${ }^{24}$ & Dichotomous \\
\hline asaved & How much were you able to save last year (in days)? & Continuous \\
\hline privacio & Deprivation index ${ }^{25}$ & Summated scale (1-2) \\
\hline
\end{tabular}

\footnotetext{
${ }^{23}$ The indicators whose summated rating has been considered are categorical variables, coded in four categories, which asses the extent to which health problems hinder doing certain basic activities such as eating alone, walking 100 meters, climbing stairs, moving at home, getting dressed and doing the personal hygiene.

${ }^{24}$ Indicates whether there have been delays in the payment of loans or mortgage, utilities' bills (water, electricity, etc), shopping.

25 The indicators whose summated rating has been employed relate to the impossibility of affording: a jacket every year, making holidays once a year, replacing damaged furniture, replacing damaged electrodomestics, meat and fish every week, new shoes every year, new cloths every year, presents to friends or relatives once a year.
} 
ApPendi X B. Summary Stati Sti CS Of Covari ATES USED In TABLe 3

\begin{tabular}{|c|c|c|c|c|}
\hline Variable & Mean & St. Dev & Min. & Max. \\
\hline Age & 47.40 & 16.86 & 16 & 97 \\
\hline Female & 0.52 & 0.50 & 0 & 1 \\
\hline \multicolumn{5}{|l|}{ Education } \\
\hline Primary & 0.37 & 0.48 & 0 & 1 \\
\hline Secondary & 0.26 & 0.44 & 0 & 1 \\
\hline University & 0.16 & 0.37 & 0 & 1 \\
\hline \multicolumn{5}{|l|}{ Civil Status } \\
\hline Single & 0.21 & 0.41 & 0 & 1 \\
\hline Divorced \& Separated & 0.04 & 0.20 & 0 & 1 \\
\hline Widow(er) & 0.06 & 0.24 & 0 & 1 \\
\hline \multicolumn{5}{|l|}{ \# employed in $\mathrm{HH}$} \\
\hline One & 0.25 & 0.43 & 0 & 1 \\
\hline Two & 0.40 & 0.49 & 0 & 1 \\
\hline More than two & 0.15 & 0.35 & 0 & 1 \\
\hline \multicolumn{5}{|l|}{ Labour Market Status } \\
\hline Unemployed & 0.04 & 0.19 & 0 & 1 \\
\hline Retired & 0.19 & 0.39 & 0 & 1 \\
\hline Inactive & 0.16 & 0.36 & 0 & 1 \\
\hline \multicolumn{5}{|l|}{ Province } \\
\hline Girona & 0.21 & 0.40 & 0 & 1 \\
\hline Lleida & 0.20 & 0.40 & 0 & 1 \\
\hline Tarragona & 0.22 & 0.41 & 0 & 1 \\
\hline \multicolumn{5}{|l|}{ Dwelling ownership } \\
\hline Mortgage & 0.29 & 0.45 & 0 & 1 \\
\hline Renting & 0.10 & 0.31 & 0 & 1 \\
\hline Other & 0.06 & 0.24 & 0 & 1 \\
\hline Life shaking event & 0.99 & 0.08 & 0 & 1 \\
\hline \multicolumn{5}{|l|}{ National I dentity } \\
\hline Equally Catalan \& Spanish & 0.37 & 0.48 & 0 & 1 \\
\hline Catalan & 0.50 & 0.50 & 0 & 1 \\
\hline Relatives live close by & 0.88 & 0.32 & 0 & 1 \\
\hline
\end{tabular}

See endnote of Table 3 for omitted categories 